\title{
Linking Emotional Intelligence to Mental Health in Chinese High School Teachers: The Mediating Role of Perceived Organizational Justice
}

\author{
Sha Shen 1,2 , Tianqi Tang ${ }^{2}$, Hong Shu ${ }^{2}$, Saidi Wang ${ }^{3}$, Xiangli Guan ${ }^{4}$, Xiangdong Yan ${ }^{5}$, \\ Yanli Wang ${ }^{2}$, Yun $\mathbf{Q i}^{2}$ and Rui Feng ${ }^{6 *}$ \\ 'Key Laboratory of China's Ethnic Languages and Information Technology of Ministry of Education, Northwest Minzu \\ University, Lanzhou, China, ${ }^{2}$ College of Educational Science and Technology, Northwest Minzu University, Lanzhou, China, \\ ${ }^{3}$ Gansu 24 Refractive New Media Technology Co., Ltd., Lanzhou, China, ${ }^{4}$ Teacher Education College, Yu Xi Normal \\ University, Yu Xi, China, ${ }^{5}$ Shanghai Hui Ye (Lan Zhou) Law Office, Lanzhou, China, ${ }^{6}$ School of Journalism and Media, \\ Yangzhou University, Yangzhou, China
}

OPEN ACCESS

Edited by:

Xiying Li,

Shaanxi Normal University, China

Reviewed by:

Zhijun Wang,

Jiangnan University,

China

Tainian Zheng,

East China Normal University, China

Nanchang Yang,

Jiangxi Normal University, China

*Correspondence:

Rui Feng

frzx0519@163.com

Specialty section:

This article was submitted to Educational Psychology, a section of the journal

Frontiers in Psychology

Received: 07 November 2021 Accepted: 25 November 2021

Published: 06 January 2022

Citation:

Shen S, Tang T, Shu H, Wang S, Guan X, Yan X, Wang Y, Qi Y and

Feng $R$ (2022) Linking Emotional

Intelligence to Mental Health in

Chinese High School Teachers: The

Mediating Role of Perceived

Organizational Justice.

Front. Psychol. 12:810727.

doi: 10.3389/fpsyg.2021.810727
Compare with other professions, teachers are reported to have a higher risk of poor mental health. This study examined the relationships between emotional intelligence, perceived organizational justice, and mental health among Chinese high school teachers. Three hundred and eighty-one high school teachers, with their age range between 21 and 50 years, were administered the Emotional Intelligence Scale, Perceived Organizational Justice Scale, and Mental Health Scale. The result found that emotional intelligence and perceived organizational justice directly influence the mental health of high school teachers. In addition, perceived organizational justice mediated the association between emotional intelligence and mental health. Moreover, the present study analyzes the different role of subtypes of perceived organizational justice on the relationships between emotional intelligence and mental health, and the results showed that the mediating effects of perceived distributive justice and interactive justice on emotional intelligence and mental health are not significant, only the perceived procedural justice mediated the relationships between emotional intelligence and teachers' mental health. The results are discussed in a conceptual context.

Keywords: emotional intelligence, mental health, perceived organizational justice, high school teachers, teachers' health

\section{INTRODUCTION}

With the strict requirements of the society on the professional development of teachers, contemporary teachers face more psychological pressure than before (Ali et al., 2021; Hollett et al., 2021). In addition, teachers have to assume multiple roles (Naylor, 2001), which makes them more prone to psychological problems (Narayanappa et al., 2016; Yang et al., 2019). Thus, compared with other professions, teachers are reported to have a higher risk of poor mental health (Stansfeld et al., 2011; Kidger et al., 2016). Riches of studies indicated that mental health is important for teachers (e.g., Narayanappa et al., 2016; Navinés et al., 2016). The mental health of teachers not only has a strong impact on teaching skills that in turn can affect the academic achievement of students (Yang et al., 2019), but also influences developing 
and establishing good relationships with students (Jennings and Greenberg, 2009), which is associated with worse mental health of students (Kidger et al., 2012; Plenty et al., 2014). The mental health of high school teachers is more important, because a number of mental problems develop in adolescence (e.g., Kim-Cohen et al., 2003; Joinson et al., 2017) and the mental health of teachers is closely related to that of students (Klusmann et al., 2016; Harding et al., 2019). Therefore, more research is needed to further clarify the factors and mechanisms that affect the mental health of high school teachers. This question is important because identifying the determinants and mechanisms of mental health among high school teachers is a critical early step for implementing interventions.

Teachers often face negative emotions in their interactions with students, family members, and colleagues (Travers, 2017); it is reasonable that emotional intelligence is regarded as one of the factors influencing mental health of teachers (Antiniene and Lekavičiene, 2017). Emotional intelligence is defined as "the extent to which a person processes emotional information adequately" (Mayer et al., 2000, 2016). Ample evidence showed that emotional intelligence is associated with classic indicators of mental health significantly (e.g., Cejudo, 2016; Singh and Bhardwaj, 2016). For example, Lea et al. (2019) used metaanalyses method to investigate the relationships between emotional intelligence and mental health, and found that higher emotional intelligence is associated with lower levels of depression, anxiety, and psychological distress and less likely to suicide (García-Sancho et al., 2014). A follow-up study showed that the students who with high emotional intelligence had fewer symptoms of depression and anxiety over time (Antiniene and Lekavičiene, 2017), and an international research has confirmed that high emotional intelligence can significantly improve the level of mental health (Kaur, 2019).

Although the previous studies indicated that emotional intelligence is related to mental health, the specific mechanisms involved in the association remain unclear. For example, mental health may be influenced by emotional intelligence through perceived organizational justice (POJ). POJ refers to employees' perception of fairness in their organizations (Eib et al., 2017), when individuals realize that a decision or process is unfair, they may develop a negative attitude toward work, reduce motivation to work (Skarlicki and Folger, 1997; Cordes, 2010). According to the emotional intelligence theory proposed by Salovey and Mayer (1990), teachers with higher emotional intelligence can better manage and use their emotions and those of others in school, can communicate well with other colleagues and leaders in school, and promote an understanding of organization-related factors and equity factors in organizations. On the contrary, individuals with relatively low emotional intelligence have difficulty in controlling their emotions and are prone to organizational injustice. In line with this model, POJ has been shown to be associated with emotional intelligence (Zeidner et al., 2004; Ouyang et al., 2015). For instance, Ouyang et al. (2015) found that there is a significant correlation between POJ and emotional intelligence. Specifically, higher level of emotional intelligence is associated with higher level of POJ. In addition, researchers have been investigating new psychosocial stressors, such as organizational justice in the context of mental health (Ferrie et al., 2006). Studies have shown that POJ is not only a major determinant of behavior and attitude outcomes, but also an important psychosocial predictor of individual health (Weiss et al., 1999). Previous studies have shown that there is a significant association between POJ and mental health. Specifically, lower level of POJ is associated with worse mental health (e.g., Hayashi et al., 2011; Rai, 2015). So, does POJ mediates the relationships between emotional intelligence and mental health?

In addition, based on the previous literature, $\mathrm{POJ}$ including three basic aspects: perceived distributive justice, perceived procedural justice, and perceived interactional justice. Perceived distributive justice refers to perception of fairness in rewards or resources that are allocated, perceived procedural justice represents an individual's view of the fairness of the process by which the administration makes decisions, and perceived interactional justice refers to the fairness of interpersonal treatment perceived by individuals in the process of decision implementation (Colquitt and Greenberg, 2003, p. 159). These subtypes of POJ are conceptually distinct (Erdogan, 2002; Ambrose and Arnaud, 2005) and have different influencing factors and different influences on individuals (Colquitt et al., 2001; Erdogan, 2002). To the authors' knowledge, no research has investigated the role of different subtypes of POJ in the relationships between emotional intelligence and mental health among teachers. So, does perceived distributive justice, perceived procedural justice, and perceived interactional justice play different roles in the relationships between emotional intelligence and mental health among high school teachers?

The present study investigates whether the relationships between emotional intelligence and mental health influenced by POJ among high school teachers. More important, the present study investigates whether the subtypes of POJ play different roles in the relationships between emotional intelligence and mental health. Based on previous studies, the present study hypotheses that the POJ mediates the relationships between emotional intelligence and mental health, and perceived distributive justice, perceived procedural justice, and perceived interactional justice play different roles in the relationships between emotional intelligence and mental health among high school teachers.

\section{MATERIALS AND METHODS}

\section{Participants}

The participants were 401 high school teachers from three high schools in northern city using utilizing convenience sampling technique. The age range was $21-50 \quad(M=35.95$, $\mathrm{SD}=7.78$ ). Any high school teacher who did not participate in a similar study can volunteer to participate. After excluding 20 incomplete questionnaires (5\%), a total of 381 responses of participants (182 males and 199 females) were used in the present study. Other demographic information is presented in Table 1. 
TABLE 1 | Socio-demographic characteristics of the participants $(n=381)$.

\begin{tabular}{lcc}
\hline & Groups & Frequency (\%) \\
Gender & 182 & \\
Female & 199 & 57.8 \\
Male & & 52.2 \\
Age & 178 & \\
$<35$ & 154 & 46.72 \\
$36-45$ & 49 & 40.42 \\
$46-50$ & & 12.86 \\
Education ground & 44 & 11.55 \\
College degree & 327 & 85.83 \\
Bachelor degree & 10 & 2.62 \\
Graduate degree & & \\
Grade of teaching & 124 & 39.90 \\
Senior one & 132 & 37.27 \\
Senior two & 125 & 22.83 \\
Senior three & & \\
\hline
\end{tabular}

TABLE 2 | Descriptive statistics and correlations for all variables $(n=381)$.

\begin{tabular}{lcccc}
\hline Variable & $\boldsymbol{M}$ (SD) & $\mathbf{1}$ & $\mathbf{2}$ & $\mathbf{3}$ \\
\hline $\begin{array}{l}\text { Emotional } \\
\text { intelligence }\end{array}$ & $56.15(12.22)$ & 1 & & \\
$\begin{array}{l}\text { Perceived } \\
\text { organizational } \\
\text { justice }\end{array}$ & $52.9(11.24)$ & $0.21 * *$ & 1 & 1 \\
$\begin{array}{l}\text { Mental health } \\
\text { (71.86 (8.76) }\end{array}$ & $0.46 * *$ & $0.45 * *$ & \\
\hline$* 0<0.01$. & & & &
\end{tabular}

At the end of the experiment, all participants received a gift worth $30 \mathrm{RMB}$. The research proposal was approved by the local academic committee.

\section{Measures \\ Emotional Intelligence Scale}

The Emotional Intelligence Scale (EIS) consists of 16 items (Law et al., 2004) and some examples of items including "I have a good understanding of my own emotions" and "I always knew if I was happy or not." Each item is answered on a seven-point scale ( $1=$ strongly disagree and $7=$ strongly agree). The scores used in the present study were calculated by summing all the scores of each item, and higher scores indicated higher emotional intelligence. The Chinese version of EIS has satisfactory reliability and validity (e.g., Hu et al., 2016; Geng, 2018). In the present study, the EIS's Cronbach alpha coefficient was 0.93 .

\section{Perceived Organizational Justice}

The scale of POJ consists of 20 items (Niehoff and Moorman, 1993) and some examples of items including "I feel I am being rewarded fairly considering the responsibilities" and "My work is arranged fairly." Each item is answered on a five-point scale ( $1=$ strongly disagree and $5=$ strongly agree). The scores used in the present study were calculated by summing all the scores of each item, and higher scores indicated experiencing higher level of organizational justice. This scale is frequently used in China and has good validity and reliability (Ouyang et al., 2015). In the present study, the POJ's Cronbach alpha coefficient was 0.91 .

\section{Mental Health Scale}

The scale of mental health scale (MHS) consists of 30 items (Cheng et al., 1990) and some examples of items including "how much sleep about worry?" and "been feeling giddy?." Each item is answered on a five-point scale $(5=$ strongly disagree and $1=$ strongly agree). The scores used in the present study were calculated by summing all the scores of each item, and higher scores indicated experiencing better mental health. This scale is frequently used in China and has good validity and reliability (Cheng et al., 1990). In the present study, the MHS's Cronbach alpha coefficient was 0.90 .

\section{Procedure}

We contacted principles of three high schools in the northern city of China to describe the purpose of the present study. They approved the study and allowed questionnaires to be sent to teachers. 401 teachers volunteered to take part in the survey. All questionnaires were completed in the school office after the teachers had completed informed consent.

\section{Ethics}

This study is based on the Declaration of Helsinki and its subsequent amendments. The study protocol was approved by the Ethics Committee of the Northwest Minzu University.

\section{Analytical Strategy}

SPSS 25.0 was used to analyze the data. First, we established the relationships between emotional intelligence, mental health, and $\mathrm{POJ}$ by the correlation analysis. Then, we conducted the two-step procedure proposed by Anderson and Gerbing (1988) and used SPSS macro PROCESS program to examine the mediating effects.

\section{RESULTS}

\section{Descriptive Statistics and Correlations for Emotional Intelligence, POJ, and Mental Health}

The descriptive statistics and the correlation test were conducted for emotional intelligence, POJ, and mental health and the results were shown in Table 2 . The results showed that emotional intelligence, $\mathrm{POJ}$, and mental health were significantly correlated $(p<0.01)$.

\section{The Analysis of the Mediating Role of POJ Between Emotional Intelligence and Mental Health}

In order to analyze the effect of emotional intelligence on mental health and the role of POJ, SPSS macro PROCESS 
program was used to test the mediating effect. The mediation model testing needs to estimate the parameters of two regression equations: First, the direct effect of independent variable (emotional intelligence) on dependent variable (mental health); Second, the mediating effect (indirect effect) of POJ on the independent variable (emotional intelligence) and the dependent variable (mental health).

If the model meets the following conditions, the mediation effect exists as: (1) Emotional intelligence has a significant effect on mental health; (2) Emotional intelligence has a significant effect on POJ; and (3) POJ has a significant effect on mental health. The results of regression analysis are shown in Table 3. The results showed that emotional intelligence predicted mental health significantly $(\beta=0.46, t=10.03$, $p<0.001)$. In addition, emotional intelligence predicted POJ significantly $(\beta=0.20, t=4.07, p<0.001)$, while POJ predicted mental health significantly $(\beta=0.37, t=8.69$, $p<0.001)$. As shown in Figure 1, POJ plays a mediating role on the relationships between emotional intelligence and mental health.

In order to obtain reliable results of mediating effect, the mediation effect was further tested using the non-parametric percentage Bootstrap which corrected by deviation. If the confidence interval of $95 \%$ Bootstrap does not contain 0 , the mediating effect is significant. The results are shown in Table 4.
The direct effect value of emotional intelligence on mental health is 0.27 , accounting for $82 \%$ of the total effect. The $95 \%$ interval is $[0.21,0.33]$, indicating that the direct effect is significant. The indirect effect of POJ on emotional intelligence and mental health is 0.05 , accounting for $18 \%$ of the total effect, with a $95 \%$ interval of $[0.26,0.88]$, indicating a significant mediating effect.

\section{The Analysis of the Different Role of the Subtypes of POJ Between Emotional Intelligence and Mental Health}

In order to analyze the effect of emotional intelligence on mental health and the different role of subtypes of POJ, SPSS macro PROCESS program was used to test the mediating effect. The three dimensions of POJ were conducted as multiple mediating variables. As shown in Figure 2, the results showed that the mediating effects of perceived distributive justice and perceived interactive justice on emotional intelligence and mental health are not significant, only the mediating effect of perceived procedural justice on emotional intelligence and mental health was found $[\beta=0.44, p<0.001, \mathrm{SE}=0.03, t=9.16,95 \% \mathrm{CI}=(0.71$, $1.16)]$, and the mediating effect accounted for $21.2 \%$ of the total effect.

TABLE 3 | The test of mediation effect $(n=381)$.

\begin{tabular}{|c|c|c|c|c|c|c|}
\hline \multirow[t]{3}{*}{ Variable } & \multicolumn{3}{|c|}{ Model 1} & \multicolumn{3}{|c|}{ Model 2} \\
\hline & \multicolumn{3}{|c|}{ Mental health } & \multicolumn{3}{|c|}{ Mental health } \\
\hline & Effect of value & SE & $t$ & Effect of value & SE & $t$ \\
\hline Emotional intelligence & 0.46 & 0.03 & $10.03^{* * * *}$ & 0.38 & 0.03 & $8.97 * * *$ \\
\hline \multicolumn{6}{|l|}{ organizational justice } & $8.69 * * *$ \\
\hline$R 2$ & & 0.21 & & & 0.34 & \\
\hline$F$ & & $12.95 * * *$ & & & $10.97 * * *$ & \\
\hline
\end{tabular}

$* * * p<0.001$

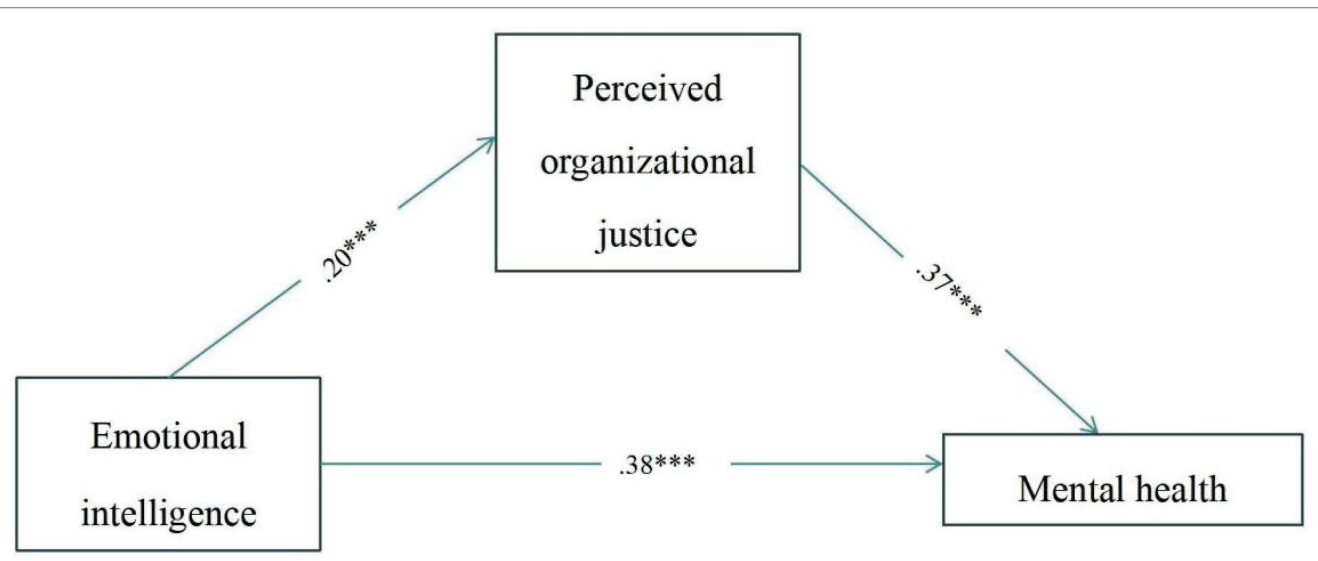

FIGURE 1 | The model of emotional intelligence, perceived organizational justice (POJ), and mental health. 


\section{DISCUSSION}

The main aim of the present study was to examine the mediating effect of POJ on emotional intelligence and mental health among Chinese high school teachers. The results of this study showed that POJ mediates the relationships between emotional intelligence and mental health. More importantly, the present study also investigated the different role of subtypes of POJ and found only the perceived procedural justice mediates the relationships between emotional intelligence and mental health of teachers. The results of the present study expand the reports of potential causes of teacher's mental health from other studies (Yang et al., 2019; Halladay et al., 2020; Ain et al., 2021) and also reveal the determinants and mechanisms between emotional intelligence and teachers' mental health. As a result of the analysis which was conducted for examining the direct role of emotional intelligence on mental health was found significant prediction. Riches of previous studies also found out that emotional intelligence had a significant relationship with mental health (e.g., GarcíaSancho et al., 2014; Lea et al., 2019). The present study found a direct predict effect of emotional intelligence on mental health. This is in line with the emotional intelligence theory (Salovey and Mayer, 1990), according to which, emotional intelligence is an important kind of ability to regulate and understand own and others' emotions (Mayer et al., 1990). Teachers often face

TABLE 4 | Bootstrap analysis of significance test of mediation effect $(n=381)$.

\begin{tabular}{lcccc}
\hline The path & $\begin{array}{c}\text { Effect } \\
\text { of value }\end{array}$ & $\begin{array}{c}\text { Effect of } \\
\text { the amount } \\
(\%)\end{array}$ & $\begin{array}{c}\text { Bootstrap 95\% } \\
\text { confidence } \\
\text { interval down line }\end{array}$ & $\begin{array}{c}\text { Bootstrap 95\% } \\
\text { confidence } \\
\text { interval upper line }\end{array}$ \\
\hline $\begin{array}{l}\text { Direct effect } \\
(A \rightarrow C)\end{array}$ & 0.27 & $82 \%$ & 0.21 & 0.33 \\
$\begin{array}{l}\text { Indirect effect } \\
(A \rightarrow B \rightarrow C)\end{array}$ & 0.05 & 18 & 0.26 & 0.88 \\
\begin{tabular}{l} 
Total effect \\
\hline
\end{tabular} & 0.33 & 100 & 0.26 & 0.39 \\
\hline
\end{tabular}

$A$, emotional intelligence; $B$, perceived organizational justice; and $C$, mental health. negative emotions (Travers, 2017), and teachers with high emotional intelligence are more likely to monitor their own feelings and emotions, and are good at using this information to guide their own thinking and actions. As a result, they are more likely to be in good mental health.

In addition, the present study emphasizes that POJ accounted for the relationships between emotional intelligence and mental health among high school teachers. This is in line with the emotional intelligence theory (Salovey and Mayer, 1990), according to which, individuals with relatively low emotional intelligence have difficulty in controlling their emotions and are prone to organizational injustice. In addition, this is in accordance with job demands-resources model (Demerouti et al., 2001). According to the job demands-resources model, the higher an individual's POJ is, the more resources they feel they have, which will weaken the impact of job requirements and alleviate individual's mental health, which implies that a high sense of organizational justice associated with better mental health.

More importantly, the present study found only the perceived procedural justice mediates the relationships between emotional intelligence and teachers' mental health. The results in line with conservation of resources theory (COR). According to COR theory, individuals strive to conserve and utilize psychological resources, such as energy and personal identity (Halbesleben et al., 2014). The theory holds that the resource loss is more critical than the resource gain (Hobfoll, 1989). The perception of procedural justice mainly comes from whether the allocation process of resources is fair or not. If individuals perceive that the allocation process is unfair to themselves, they will perceive that their resources are reduced. Such perception of reduced resources will exert pressure on individuals and lead them to adopt some defensive strategies to avoid resource loss in future (Halbesleben et al., 2014), thus leading to a decline of their mental health.

There are some limitations in this study. First, this study is cross-sectional, no causal conclusions can be drawn. More longitudinal studies should be conducted in the future to verify the causal relationship among these variables. Second, this study was conducted among Chinese teachers, the results obtained may

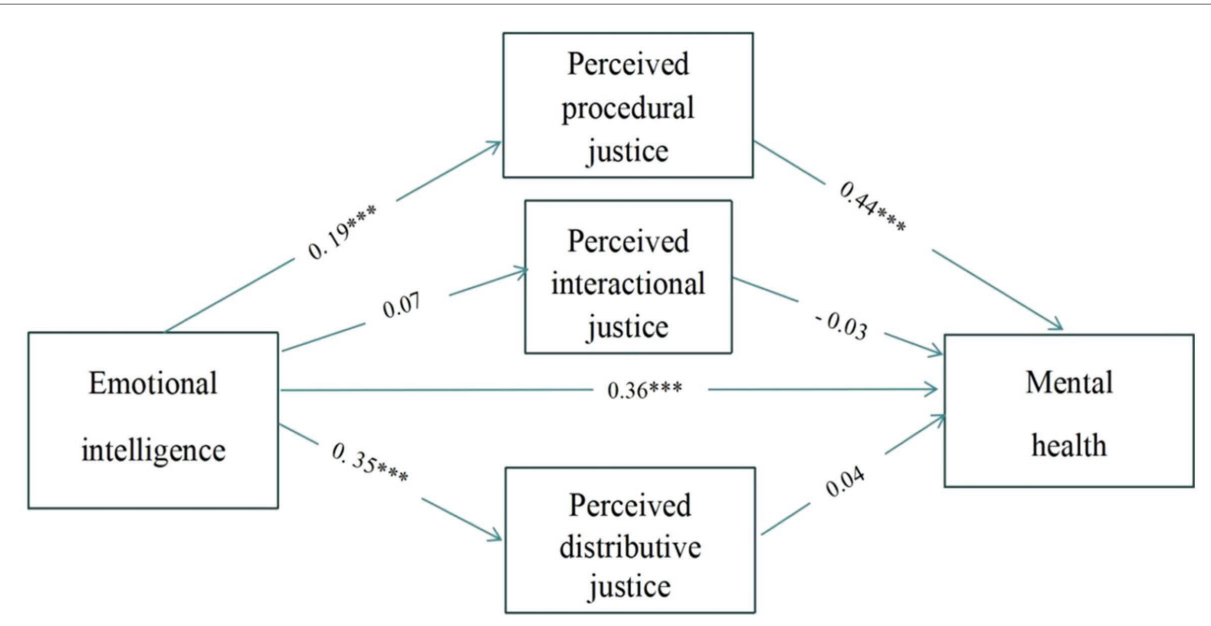

FIGURE 2 | The model of emotional intelligence, different of subtypes of perceived organizational justice and mental health. 
not be generalized to relevant populations in other countries. Third, the participants were mostly from northern cities of China, the representativeness of the sample should be expanded in future studies.

Despite its limitations, this study is the first attempt to investigate the underlying mechanism of POJ between emotional intelligence and mental health among Chinese high school teachers. The results indicate that emotional intelligence influences mental health by POJ, and only the perceived procedural justice mediates the relationships between emotional intelligence and teachers' mental health. These results may provide valuable information for the intervention design aimed at reducing the factors affecting teachers' mental health. On the one hand, improving teachers' emotional intelligence through training can influence the relationships between emotional intelligence and mental health. On the other hand, for teachers with low emotional intelligence, the relationships between emotional intelligence and mental health can be affected by improving perceived procedural justice.

\section{DATA AVAILABILITY STATEMENT}

The raw data supporting the conclusions of this article will be made available by the authors, without undue reservation.

\section{ETHICS STATEMENT}

The studies involving human participants were reviewed and approved by the Ethics Committee of the College of Educational

\section{REFERENCES}

Ain, N., Munir, M., and Suneel, I. (2021). Role of emotional intelligence and grit in life satisfaction. Heliyon 7:e06829. doi: 10.1016/j.heliyon.2021.e06829

Ali, M. S., Jalal, H., and Naoreen, B. (2021). Online teaching, psychological state, and job satisfaction: teachers' perspective during covid-19 pandemic. Turk. Online J. Dist. Educ. 20, 358-364. doi: 10.17051/ilkonline.2021.02.37

Ambrose, M., and Arnaud, A. (2005). "Are procedural justice and distributive justice conceptual distinct?" in The Handbook of Organizational Justice. eds. J. Greenberg and J. A. Colquitt (Mahwah, NJ: Erlbaum), 59-84.

Anderson, J. C., and Gerbing, D. W. (1988). Structural equation modeling in practice: a review and recommended two-step approach. Psychol. Bull. 103, 411-423. doi: 10.1037/0033-2909.103.3.411

Antinienè, D., and Lekavičienè, R. (2017). Psychological and physical well-being of Lithuanian youth: relation to emotional intelligence. Medicina 53, 277-284. doi: $10.1016 /$ j.medici.2017.05.008

Cejudo, J. (2016). Relationship between emotional intelligence and mental health in school counselors. Electron. J. Res. Educ. Psychol. 14, 131-154. doi: 10.14204/ ejrep.38.15025

Cheng, T., Wu, J., Chong, M., and Williams, P. (1990). Internal consistency and factor structure of the Chinese health questionnaire. Acta Psychiatr. Scand. 82, 304-308. doi: 10.1111/j.1600-0447.1990.tb01389.x

Colquitt, J. A., Conlon, D. E., Wesson, M. J., Porter, C. O. L. H., and Ng, K. Y. (2001). Justice at the millennium: a meta-analytic review of 25 years of organizational justice research. J. Appl. Psychol. 86, 425-445. doi: 10.1037/0021-9010.86.3.425

Colquitt, J. A., and Greenberg, J. (2003). "Organizational justice: a fair assessment of the state of the literature," in Organizational Behavior. ed. J. Greenberg. 2nd ed (New Jersey: Lawrence Erlbaum Associates Inc)

Cordes, H. (2010). Flight from unfairness: effects of perceived injustice on emotional exhaustion and employee withdrawal. J. Bus. Psychol. 25, 409-428. doi: $10.2307 / 40682662$
Science and Technology of Northwest Minzu University. The patients/participants provided their written informed consent to participate in this study.

\section{AUTHOR CONTRIBUTIONS}

SS, XG, RF, and SW proposed the original thoughts. TT, XY, YW, YQ, and HS collected the data. All authors contributed to the article and approved the submitted version.

\section{FUNDING}

This work was supported by the Key Laboratory of Ethnic Languages and Information Technology of Ministry of Education of China, Northwest Minzu University, Lanzhou, Gansu, China (KFKT202013, KFKT202016, KFKT202012, and 1001161310). The Young Doctor Foundation of Higher Education in Gansu Province "Research on the educational effect mechanism of the socialist core value 'unity of knowing and doing' of college students for nationalities in the new era" (no. 2021QB-071). The 14th five-year planning project of Education science in Gansu Province "A study on the core behavior of patriotism of children in the new era" (no.: GS[2021]GHB1836). Fundamental Research Funds for the Central Universities "Research on influencing factors of online education in postepidemic era” (no.: 31920210125).

Demerouti, E., Bakker, A. B., Nachreiner, F., and Schaufeli, W. B. (2001). The job demands-resources model of burnout. J. Appl. Psychol. 86, 499-512. doi: 10.1037/0021-9010.86.3.499

Eib, C., Soenen, G., Fraccaroli, F., and Sverke, M. (2017). "Why Should Organizations Treat Their Employees Fairly? Definition, Relevance, and Consequences of Justice at Work," in An Introduction to Work and Organizational Psychology: An International Perspective. eds. N. Chimel, F. Fraccaroli, and M. Sverke (Chichester, London: John Wiley \& Sons), 276-294.

Erdogan, B. (2002). Antecedents and consequences of justice perceptions in performance appraisals. Hum. Resour. Manag. Rev. 12, 555-578. doi: 10.1016/ S1053-4822(02)00070-0

Ferrie, J. E., Head, J., Shipley, M. J., Vahtera, J., Marmot, M. G., and Kivimäki, M. (2006). Injustice at work and incidence of psychiatric morbidity: the Whitehall II study. Occup. Environ. Med. 63, 443-450. doi: 10.1136/oem.2005.022269

García-Sancho, E., Salguero, J. M., and Fernández-Berrocal, P. (2014). Relationship between emotional intelligence and aggression: a systematic review. Aggress. Violent Behav. 19, 584-591. doi: 10.1016/j.avb.2014.07.007

Geng, Y. (2018). Gratitude mediates the effect of emotional intelligence on subjective well-being: a structural equation modeling analysis. J. Health Psychol. 23, 1378-1386. doi: 10.1177/1359105316677295

Halbesleben, J., Neveu, J. P., Paustian-Underdahl, S. C., and Westman, M. (2014). Getting to the |"corl": understanding the role of resources in conservation of resources theory. J. Manag. 40, 1334-1364. doi: 10.1177/0149206314527130

Halladay, J., Bennett, K., Weist, M., Boyle, M., Manion, I., Campo, M., et al. (2020). Teacher-student relationships and mental health help seeking behaviors among elementary and secondary students in Ontario Canada. J. Sch. Psychol. 81, 1-10. doi: 10.1016/j.jsp.2020.05.003

Harding, S., Morris, R., Gunnell, D., Ford, T., Hollingworth, W., Tilling, K., et al. (2019). Is teachers' mental health and wellbeing associated with students' mental health and wellbeing? J. Affect. Disord. 242, 180-187. doi: 10.1016/j.jad.2018.08.080

Hayashi, T., Odagiri, Y., Ohya, Y., Tanaka, K., and Shimomitsu, T. (2011). Organizational justice, willingness to work, and psychological distress: results 
from a private japanese company. J. Occup. Environ. Med. 53, 174-181. doi: 10.1097/JOM.0b013e31820665cd

Hobfoll, S. E. (1989). Conservation of resources: a new attempt at conceptualizing stress. Am. Psychol. 44:513. doi: 10.1037/0003-066X.44.3.513

Hollett, R. C., McMahon, M., and Monson, R. (2021). Associating psychological factors with workplace satisfaction and position duration in a sample of international school teachers. Front. Psychol. 11:3949. doi: 10.3389/fpsyg.2020.601554

Hu, C., Wang, S., Wang, Y. H., Chen, C., and Jiang, D. Y. (2016). Understanding attraction in formal mentoring relationships from an affective perspective. J. Vocat. Behav. 94, 104-113. doi: 10.1016/j.jvb.2016.02.007

Jennings, P. A., and Greenberg, M. T. (2009). The prosocial classroom: teacher social and emotional competence in relation to student and classroom outcomes. Rev. Educ. Res. 79, 491-525. doi: 10.3102/0034654308325693

Joinson, C., Kounali, D., and Lewis, G. (2017). Family socioeconomic position in early life and onset of depressive symptoms and depression: a prospective cohort study. Soc. Psychiatry 52, 95-103. doi: 10.1007/s00127-016-1308-2

Kaur, R. (2019). Relationship of emotional intelligence with mental health among employees. Working Papers 8, 2277-7733.

Kidger, J., Araya, R., Donovan, J., and Gunnell, D. (2012). The effect of the school environment on the emotional health of adolescents: a systematic review. Pediatrics 129, 925-949. doi: 10.1542/peds.2011-2248

Kidger, J., Brockman, R., Tilling, K., Campbell, R., Ford, T., Araya, R., et al. (2016). Teachers' wellbeing and depressive symptoms, and associated risk factors: a large cross sectional study in English secondary schools. J. Affect. Disord. 192, 76-82. doi: 10.1016/j.jad.2015.11.054

Kim-Cohen, J., Caspi, A., Moffitt, T. E., Harrington, H. L., and Poulton, R. (2003). Prior juvenile diagnoses in adults with mental disorder: developmental follow-back of a prospective-longitudinal cohort. Arch. Gen. Psychiatry 60, 709-717. doi: 10.1001/archpsyc.60.7.709

Klusmann, U., Richter, D., and Lüdtke, O. (2016). Teachers' emotional exhaustion is negatively related to students' achievement: evidence from a large-scale assessment study. J. Educ. Psychol. 108, 1193-1203. doi: 10.1037/edu0000125

Law, K. S., Wong, C. S., and Song, L. J. (2004). The construct and criterion validity of emotional intelligence and its potential utility for management studies. J. Appl. Psychol. 89:483. doi: 10.1037/0021-9010.89.3.483

Lea, R. G., Davis, S. K., Mahoney, B., and Qualter, P. (2019). Does emotional intelligence buffer the effects of acute stress? A systematic review. Front. Psychol. 10:810. doi: 10.3389/fpsyg.2019.00810

Mayer, J. D., Caruso, D. R., and Salovey, P. (2000). "Selecting a measure of emotional intelligence: the case for ability scales," in The handbook of emotional intelligence: Theory, development, assessment, and application at home, school, and in the workplace. eds. R. Bar-On and J. D. A. Parker (San Francisco: Jossey-Bass), 320-342.

Mayer, J. D., Dipaolo, M., and Salovey, P. (1990). Perceiving affective content in ambiguous visual stimuli: a component of emotional intelligence. J. Pers. Assess. 54, 772-781. doi: 10.1080/00223891.1990.9674037

Mayer, J. D., Caruso, D. R., and Salovey, P. (2016). The ability model of emotional intelligence: principles and updates. Emot. Rev. 8, 290-300. doi: $10.1177 / 1754073916639667$

Narayanappa, S., Manjunath, R., and Kulkarni, P. (2016). Mental health risk factors influencing metabolic syndrome among secondary school teachers of Mysore city. Int. J. Community Med. Public Health 3, 998-1009. doi: 10.18203/2394-6040.ijcmph20160978

Navinés, R., Martín-Santos, R., Olivé, V., and Valdés, M. (2016). Work-related stress: implications for physical and mental health. Med. Clin. 146, 359-366. doi: $10.1016 /$ j.medcli.2015.11.023

Naylor, C. (2001). Teacher Workload and Stress: An International Perspective on Human Costs and Systemic Failure. BCTF Research Report. British
Columbia Teachers' Federation, 100-550 West 6th Avenue, Vancouver, BC, Canada.

Niehoff, B. P., and Moorman, R. H. (1993). Justice as a mediator of the relationship between methods of monitoring and organizational citizenship behavior. Acad. Manag. J. 36, 527-556. doi: 10.5465/256591

Ouyang, Z., Sang, J., Li, P., and Peng, J. (2015). Organizational justice and job insecurity as mediators of the effect of emotional intelligence on job satisfaction: a study from China. Personal. Individ. Differ. 76, 147-152. doi: 10.1016/j. paid.2014.12.004

Plenty, S., Östberg, V., Almquist, Y. B., Augustine, L., and Modin, B. (2014). Psychosocial working conditions: an analysis of emotional symptoms and conduct problems amongst adolescent students. J. Adolesc. 37, 407-417. doi: 10.1016/j.adolescence.2014.03.008

Rai, S. (2015). Organizational justice and employee mental health's moderating roles in organizational identification. South Asian J. Glob. Bus. Res. 4, 68-84. doi: 10.1108/SAJGBR-01-2014-0006

Salovey, P., and Mayer, J. D. (1990). Emotional intelligence. Imagin. Cogn. Pers. 9, 185-211. doi: 10.2190/DUGG-P24E-52WK-6CDG

Singh, D. P., and Bhardwaj, B. K. (2016). Emotional intelligence and adjustment of sports persons. Int. J. Indian Psychol. 3:86. doi: 10.25215/0304.066

Skarlicki, D. P., and Folger, R. (1997). Retaliation in the workplace: the roles of distributive, procedural, and interactional justice. J. Appl. Psychol. 82, 734-443. doi: 10.1037//0021-9010.82.3.434

Stansfeld, S. A., Rasul, F. R., Head, J., and Singleton, N. (2011). Occupation and mental health in a national UK survey. Soc. Psychiatry Psychiatr. Epidemiol. 46, 101-110. doi: 10.1007/s00127-009-0173-7

Travers, C. (2017). Current knowledge on the nature, prevalence, sources and potential impact of teacher stress. Educ. Stress 2, 23-54. doi: 10.1007/978-3-319-53053-6_2

Weiss, H. M., Suckow, K., and Cropanzano, R. (1999). Effects of justice conditions on discrete emotions. J. Appl. Psychol. 84:786. doi: 10.1037/0021-9010.84.5.786

Yang, R., You, X., Zhang, Y., Lian, L., and Feng, W. (2019). Teachers' mental health becoming worse: the case of China. Int. J. Educ. Dev. 70:102077. doi: 10.1016/j.ijedudev.2019.102077

Zeidner, M., Matthews, G., and Roberts, R. D. (2004). Emotional intelligence in the workplace: a critical review. Appl. Psychol. 53, 371-399. doi: 10.1111/j. 1464-0597.2004.00176.x

Conflict of Interest: SW was employed by Gansu 24 refractive new media technology Co., Ltd. XY was employed by Shanghai Hui Ye (Lan Zhou) Law Office.

The remaining authors declare that the research was conducted in the absence of any commercial or financial relationships that could be construed as a potential conflict of interest.

Publisher's Note: All claims expressed in this article are solely those of the authors and do not necessarily represent those of their affiliated organizations, or those of the publisher, the editors and the reviewers. Any product that may be evaluated in this article, or claim that may be made by its manufacturer, is not guaranteed or endorsed by the publisher.

Copyright (c) 2022 Shen, Tang, Shu, Wang, Guan, Yan, Wang, Qi and Feng. This is an open-access article distributed under the terms of the Creative Commons Attribution License (CC BY). The use, distribution or reproduction in other forums is permitted, provided the original author(s) and the copyright owner(s) are credited and that the original publication in this journal is cited, in accordance with accepted academic practice. No use, distribution or reproduction is permitted which does not comply with these terms. 